\title{
ATTITUDE CHANGE AND ACTION IN A COURSE AIMING FOR THE SOCIAL JUSTICE TURN
}

\author{
Lauren B. Cattaneo, Jenna M. Calton, Rachel Shor, Syeda I. Younus, Kris T. \\ Gebhard, Stephanie Hargrove, Nour Elshabassi, and Batool Al-Shaar
}

\section{Abstract}

This article describes a longitudinal study of a social justice-oriented service-learning course at a large diverse university. The course elucidates the social causes of social problems, with poverty as a case example. Research shows that service-learning meaningfully impacts college students but that outcomes vary across courses and students, and scholars have called for greater attention to these sources of variation and mechanisms of change. Placing social justice at the center of this inquiry means focusing on a particular subset of outcomes and student characteristics. The study evaluated changes in outcomes central to social justice pedagogy, including explicit and implicit attitudes, explored whether these changes were moderated by students' social class, and tested whether attitude changes predicted civic behavior a year later. Compared to a control group ( $n=172)$, students who took the course ( $n=113)$ increased systemic attributions for poverty, decreased individualistic attributions, increased their awareness of class privilege, and increased their general social justice attitudes. They increased their civic action in terms of political action and general civic engagement. Implicit attitudes did not shift. Students who experienced more financial stress changed less in terms of deficit-oriented thinking but changed more in terms of system-oriented thinking. Pedagogical implications for social justice-oriented courses are discussed, including the need to consider techniques targeting deficitoriented thinking and system-oriented thinking separately.

Scholarship has provided consistent evidence that service-learning courses have a positive impact on students across a range of academic, psychological, interpersonal, and civic outcomes (e.g., Celio et al., 2011; Eyler \& Giles, 1999; Holsapple, 2012; Novak et al., 2007; Warren, 2012). When social justice is at the center of service learning, a subset of learning outcomes comes to the fore, and achieving those outcomes has implications beyond the individual student. As articulated by Grain and Lund (2016):

Herein lies the greatest dilemma within the field of service-learning: It has the capacity to exacerbate inequality when done poorly, and to be a promising equalizing force when done well. Its effectiveness in 
advancing the goals of social justice, rather than causing harm . . . is contingent upon a conscious shift in the conceptualization of service-learning-the social justice turn. (p. 48)

Mitchell (2008) has termed this model of service-learning pedagogy "critical service-learning," in which courses "bring attention to social change through dispelling myths of deficiency while acknowledging how systems of inequality function in our society" (p. 55). Proponents expect not only positive outcomes for students through this methodology but also positive societal outcomes, radiating forward through the actions of students over time.

Scholarship exploring service-learning in general has demonstrated that multiple factors can modify outcomes and has suggested that researchers explore the impact of course characteristics and models in order to articulate generalizable mechanisms of change (e.g., Celio et al., 2011; Conner \& Erickson, 2017; Moely, McFarland, et al., 2002). Such scholarship has the potential to inform course design and implementation. This study explores the nature of student change in a service-learning course that is explicitly oriented toward social justice, evaluating its impact on both student thinking and behavior. As a result, we respond to several critiques in the broader literature.

Most important, the outcomes we evaluate are not unique to our course but are couched within a pedagogical framework consistent with the "social justice turn." Specifically, we explore whether students' attributions for social problems become less focused on the failings of individuals and more focused on the nature of systems. Both the pedagogical framework and the link between outcomes and specific techniques allow for generalizability of findings (Holsapple, 2012). In addition, scholars have critiqued studies that measure intentions to act rather than assessing behavior; we test the connection between attitude changes and civic action a year after taking the course. Finally, both service-learning and civic engagement scholarship have noted a gap in research on how students' social identity might affect their experience of a course, particularly for economically marginalized students (e.g. Conley \& Hamlin, 2009). In evaluating a course that focuses on poverty, we respond to that critique by exploring the role of students' social class on attitude changes.

\section{Literature Review}

\section{The Social Justice Turn}

In a recent paper, Grain and Lund (2016) describe the current political landscape as one that demands an intentional "taking stock" moment from service-learning practitioners and scholars in higher education. They call for an intensified focus on inequity and the ways in which service-learning might contribute to or elucidate it. While they note that neither the theme of social inequity nor the connection between service-learning and the desire for social change is by any means new, they argue that there is "an immediate need for a shift from their marginalized position to a more central focus" (p. 46). 
Concretely, bringing social justice to the center of service-learning is reflected in several themes in the classroom (Grain \& Lund, 2016). First, scholars have argued that the service in service-learning must guide students in identifying and interrogating structural inequalities rather than falling into a charity paradigm (e.g., Mitchell, 2008, 2013). Indeed, the charity paradigm may only strengthen students' sense of placement in the hierarchy above a needy other, alleviating guilt while leaving power dynamics unseen and unquestioned (Marullo \& Edwards, 2000). Second, centering social justice includes a critique and rejection of White normativity, both through the integration of diverse voices in curriculum and through pedagogy that assumes a diverse student body (e.g., Mitchell et al., 2012). Finally, a social justice focus is represented in the embrace of emotional distress or discomfort in the classroom. Scholars have used various terms to represent the function of emotion in learning in this way: for example, a "pedagogy of discomfort" (Zembylas \& McGlynn, 2012) or facilitating transformational learning through the creation of "disorienting dilemmas" (Stanlick, 2015). In sum, the social justice turn is a pedagogy that puts the recognition, interrogation, and discomfort of inequity at the forefront of course design, content, and implementation.

It is clear from the rich literature reviewed by Grain and Lund (2016) that there is considerable agreement about the spirit and values underlying the centering of social justice. However, the implementation of this approach is complex, and the question of how particular techniques contribute to aspects of its success requires more exploration.

\section{Description of a Critical Service-Learning Course}

The first author developed the undergraduate course Community Engagement for Social Change at a large, diverse, public university in the mid-Atlantic United States. Consistent with the idea of centering social justice, the main goals of the class are to teach students to recognize and understand the social causes of social problems and to facilitate their interest in addressing those problems. The development and content of the course is described in detail elsewhere (Cattaneo et al., 2019). Here we provide a brief overview for context and note the ways in which the course fits within the paradigm described above.

There are several phases of the course, which is worth three credits (standard for our university) and meets for 2.5 hours weekly. We begin by introducing the concept of victim blaming (Ryan, 1971), and students learn to identify deficit versus structural ideology. Students come to understand that both ideologies can be well intended, infused with concern for people who suffer. However, a deficit ideology blames the victim by locating the social problem (and thus the thing that needs fixing) within the individual, whereas a structural ideology draws focus to the systems that cause and perpetuate the suffering, generation after generation. Developing interventions from a deficit perspective can help individuals in important ways, but such an approach does not address the enduring causes of social problems and thus fails to prevent the next group of individuals from suffering.

Next, the class is introduced to the multi-level model, adapted from Bronfenbrenner's (Bronfenbrenner \& Ceci, 1994) ecological model, as a guiding framework. The model is our method for teaching a complex view of social problems that emphasizes systemic factors, but in a way that students can articulate and retain. The 
class then transitions to an in-depth analysis of poverty as an example of an enduring social problem. Using the model, students learn to identify the factors that cause and/or perpetuate or ameliorate poverty at three levels: the systemic level (e.g., governmental and organizational policies, cultural narratives, systems of education and health), the relationship level (e.g., stress contagion, stress buffering, social capital), and the individual level (primarily impacts of poverty that make it difficult to escape, such as chronic health problems, internalized stigma, and survival-focused coping). The class then learns about examples of interventions that target each of the levels. Finally, students work in groups to apply the multi-level model to a social problem other than poverty and present the results of that application creatively in class.

Over the course of the semester, all students perform a total of 20 hours of service in an organization that serves clients experiencing poverty. Partnerships with these organizations have been developed over time by the instructor. Placements are designed so that all students have direct contact with clients while ensuring that our class does not take more from organizations (in terms of training and coordination) than we give (Cattaneo, Shor, et al., 2019).

While instructors of the course thus far have been faculty and graduate students in psychology, the class itself is a "synthesis" class. This designation means that the course fulfills a general graduation requirement for the university and that it synthesizes the perspectives of multiple fields. Students who take the course are majority psychology majors, but students from other majors have also enrolled and succeeded. Thus, we anticipate that the strategies and outcomes we describe here are applicable beyond the context of psychology. Indeed, since the conclusion of the study, the course has been offered in the interdisciplinary context of the Honors College at our university, fulfilling a civic engagement requirement for a wide range of majors.

The course integrates reflection in multiple ways throughout the semester. Within and between every class, students are engaged in the application of course concepts to experience and are guided in reflecting on what the impact is on their own thinking. Students reflect individually through regular structured written assignments that often direct them to consider how something does or does not apply to what they have experienced at their placement. Since the richness of experience at placements vary, the class also draws on first-person narratives in readings, podcasts, and TED talks in order to give students an array of material to consider. In-class reflection is both ad-hoc and structured. Instructors may introduce an interesting point from student written work for the class to reflect on as a large group and/or divide the class into "placement groups," allowing students to share experiences in similar settings. The combination of in-class and individual reflection opportunities ensures not only that all students reflect but also that they receive feedback from both instructors and classmates on their reflections.

\section{In What Ways Does the Course Center Social Justice?}

Community Engagement for Social Change emphasizes the framework of social inequity and systemic oppression throughout the semester, repeatedly linking student experiences in the community to those larger themes. For example, students learn to unpack power dynamics through in-class exercises and then write a reflection about who has which kinds of power in their community placement. These early experiences set the stage to interrogate power dynamics and students' place within them throughout the course. 
With respect to the nature of student service, the course falls short of the ideal of critical service-learning (Mitchell, 2008), in that many of the placements are a more traditional format, with students in the helper role as opposed to working collaboratively with community members. Mindful of this growth area in the course, from the first day we introduce vocabulary to understand what a charity paradigm looks like and to discuss the ways in which we may be drawn to a charitable rather than a justice-oriented way of thinking. For example, we recognize the ways in which a deficit orientation alleviates guilt and increases our sense of control over our own lives (Cattaneo, Shor, et al., 2019). We guide students in thinking critically about the nature of placements and how they influence their understanding of course concepts. We view this combination-more traditional placements with critical reflection - as a middle ground between the charity paradigm and the ideal of the critical service-learning model.

The course is also specifically attuned to the risk of over-representing privileged voices in the classroom and curriculum. For example, we bring in a speaker's bureau from a national advocacy organization for people who are homeless in order to include specific marginalized voices, and we assist students in bringing in marginalized voices in their own research projects at the end of the semester. We are also explicit about the possibility that students and instructors may have had some of the experiences we are discussing (discrimination, poverty, racism) and that we value but do not require the sharing of those experiences, either one-on-one or in class.

Finally, the social justice turn includes an acknowledgment of the necessity and value of discomfort in the classroom. Consistent with this theme, in Community Engagement for Social Change, we invoke Martin Luther King Jr.'s term "creative maladjustment” on the very first day of class (King, 1968). Similar to Grain and Lund's (2016) terminology of “critical hope," King's phrase encourages us to remain "maladjusted” to injusticenoticing and remaining uncomfortable with the inequity we encounter. However, the word "creative" reminds us to be fueled by this comfort rather than drown in it. This ideal is easier said than done, and we repeatedly draw attention to and wrestle with our discomfort together as the semester goes on-both in the classroom and one-on-one with students as needed. We have the explicit intention to provide both the disorienting experiences and the brave space necessary for transformative learning (Stanlick, 2015).

In sum, the course aims to center social justice in a way that is consistent with the call to action in the broader field. As such, it provides an opportunity to investigate whether this pedagogy reaches the social justice-oriented outcomes one would expect, both in terms of students' thinking and in terms of their choices after the course is done.

\section{Attitudes as Predictors of Civic Action}

\section{When Social Justice Is Centered, Which Attitudes Should Shift?}

Research has documented that service-learning has a positive impact on a range of pro-social variables (Astin et al., 2006; Whitley \& Yoder, 2015). Most relevant to the social justice turn, Eyler and Giles (1999) describe the way in which students may shift not only beliefs about particular issues but also the lens through which they view the world. They term this type of shift "perspective transformation" and link it to the concept of transfor- 
mational learning articulated by Mezirow (2000; see also Stanlick, 2015). Service-learning creates the possibility for this type of profound change, as it brings students into contact with people and situations outside their usual context, potentially challenging fundamental beliefs. The degree to which students shift their thinking after this type of "disorienting" experience depends in part on the particulars of the course.

As noted in large-scale studies and meta-analyses of the outcomes of service learning (Astin et al., 2006; Conway et al., 2009; Whitley \& Yoder, 2015), positive effects are well documented in the aggregate, but there is a need for specificity in linking particular types of classes with particular outcomes. A course centering social justice should lead students to increase their awareness of social inequity and to attribute problems less to individual deficiency and more to systemic causes. Indeed, in their foundational work on service-learning outcomes, Eyler and Giles (1999) documented a shift in a system orientation toward problems and solutions among students who were involved in service-learning courses and a greater shift when they reported that action and reflection were more integrated in the course. However, our recent work has suggested that a deficit orientation and a system orientation may co-exist (Cattaneo, Shor, et al., 2019), so that they should be considered independently rather than as a single continuum. Considering deficit and system orientations as distinct also suggests that they might be influenced differently and that they might be associated with different outcomes.

If shifting deficit-oriented and systemic thinking is the heart of social justice pedagogy, these attitudes should predict engagement in civic behaviors after the course is over. While links between service-learning and behavior have been established in prior work, the degree to which particular attitude changes lead to particular types of civic action needs to be further explored. More fine-grained analyses are necessary in order to inform social justice pedagogy.

\section{Implicit versus Explicit Attitudes}

To evaluate attitude change, the service-learning literature tends to measure explicit attitudes—those that are consciously held and self-reported by participants. However, there may be considerable advantages to assessing attitudes that are less susceptible to impression management, particularly in a classroom setting in which students may be unable or unwilling to report their beliefs about socially sensitive topics. Implicit attitudes are automatic and often non-conscious; they are formed by experience and are heavily influenced by one's exposure to the dominant narratives (Banaji \& Greenwald, 2013).

The tool most commonly used to measure implicit attitudes is the Implicit Association Test (IAT; Nosek et al., 2011), which measures the strength of participants' negative associations with stigmatized social identity groups. A growing literature uses the IAT in order to test the effectiveness of educational techniques in shifting implicit bias. This literature has shown mixed results. In a recent review, Sukhera et al. (2019) reported that of 15 studies using experiential learning, five showed a pre-post change in implicit bias. In the context of servicelearning, one study showed a decrease in ageist attitudes after contact with elders in a service project (Kogan \& Schoenfeld-Tacher, 2018), and another showed decreases in negative associations of people with mental illness 
after a service project (Barney et al., 2017). These mixed results suggest that the impact of particular techniques on implicit bias needs to continue to be explored.

In addition to mixed evidence about the mutability of implicit attitudes, the literature is mixed on the predictive strength of implicit over explicit attitudes (Greenwald et al., 2009; Oswald et al., 2013). One possibility is that the predictive strength of implicit attitudes varies by topic. There is research to suggest that implicit attitudes about socially sensitive topics (e.g., racism) may predict corresponding behaviors better than explicit bias (Greenwald et al., 2009; Hofmann et al., 2005). Here again, the mixed evidence about the link between implicit attitudes and behavior suggests more exploration is warranted.

\section{Social Class and Service-Learning}

The social justice turn includes a recognition of the bias that can be infused into service-learning curriculum. In much scholarship related to service-learning and attitude change, there is an implicit assumption that students have not themselves experienced the hardships they are witnessing in their placements or discussing in the classroom and that they have little in common with those they encounter in service (Henry, 2005). In fact, the whole notion of a "disorienting dilemma" could be interpreted to mean that students are learning about injustice in a way that is inconsistent with their life experience thus far. This assumption is obviously problematic and could be experienced by students with marginalized identities as a micro-aggressive statement that they do not belong. In the context of economic marginalization, such interactions have been termed "interpersonal classism" (Langhout et al., 2009). A robust body of literature suggests that students who come from economically marginalized backgrounds struggle to experience a sense of belonging in college (e.g., Rubin \& Wright, 2017) and have a lower rate of degree completion regardless of their level of ability (Conley \& Hamlin, 2009; Tinto, 2006). Because social class is an invisible identity, it is easy for faculty and other students to assume that no one in the room has, for example, ever lived in a homeless shelter or gone without food.

In one semester of the Community Engagement for Social Change class described earlier, this point became very clear. On the last day of the class, students were discussing the impact the course had had on them. One student raised her hand to say that she had been having a very difficult semester, financially. She said that it was "strange" to be hungry while discussing hunger in class. It is essential that faculty explicitly make room for the possibility that a student is experiencing exactly the issue being discussed in class and consider their pedagogy in that light.

Qualitative studies have documented the positive potential of service-learning for those who are low income but have also documented that their experience of it may vary from that of students who come from more resources (Lee, 2005; Yeh, 2010). In particular, the growth in critical consciousness that can be promoted by justice-oriented service-learning is likely to be somewhat different for students who come from economic marginalization, given that it has relevance for their personal experience. Here again, a more fine-grained analysis is necessary in order to inform justice-oriented pedagogy. 


\section{Current Study}

\section{Questions/Hypotheses}

1. We hypothesize that students who take Community Engagement for Social Change (CESC), compared with students who do not take the class, will increase their social justice-oriented attitudes and decrease their deficit-oriented thinking. We hypothesize these changes will last for the year post-course.

a. On an exploratory basis, we explore whether implicit attitudes change for students who take the course.

2. We hypothesize that students who take CESC, compared with those who do not take the course, will engage in more civic action a year after the course ends.

3. We hypothesize that the attitudes that change as a result of the course will predict civic action a year later.

a. As an exploratory question, we investigate the links between specific attitude changes and types of civic action.

4. We explore how students' social class moderates the process of attitude change during the semester.

\section{Method}

\section{Participants and Procedures}

Our public university is one of the most diverse in the region. It enrolls roughly 25,000 undergraduates, the vast majority of whom attend full time. A significant minority (38\%) report being first-generation college students, and just under half identify as White (43\%); the largest minority groups are Asian (19\%), Black or African American (10.8\%), and Hispanic (13.5\%). Approximately 1,000 students are psychology majors. The course (CESC) fulfills two academic requirements that make it attractive to students: it is a "synthesis" course, which is a requirement for graduation, and it counts as a course in "applied psychology," which is a requirement for all psychology majors.

All participants were psychology majors in their junior or senior year of college. As incentives, we offered both pay and research credit. In order to recruit students who were not taking the class, we posted announcements on the psychology department electronic mailing list and, with instructor permission, emailed students in courses that required research participation. To recruit CESC students, members of the research team who were not instructors for the course sent emails before the course began to offer students the opportunity to participate and then made a brief announcement in class for the first two weeks to offer the opportunity again. We offered $\$ 10$ for Time 1 completion and $\$ 20$ for completion of Time 2 and Time 3. Three different cohorts of CESC students participated, and data collection lasted three years. All procedures were approved by our institutional review board and followed our (American Psychological Association) code of ethics with respect to the treatment of research participants. 
Table 1

Demographic Statistics for Course and Control Group Students

\begin{tabular}{|c|c|c|c|c|}
\hline Variable & $\begin{array}{l}\text { Total sample } \\
(N=285)\end{array}$ & $\begin{array}{l}\text { Service-learning students } \\
\qquad(n=112)\end{array}$ & $\begin{array}{l}\text { Control group students } \\
(n=173)\end{array}$ & $\begin{array}{c}\text { Significant differences } \\
\text { between groups }\end{array}$ \\
\hline $\mathrm{Age}^{\mathrm{a}}$ & $23 / 21(21)$ & $24 / 22(21)$ & $23 / 21(21)$ & None \\
\hline Female & $227(81.4 \%)$ & $85(73.9 \%)$ & $142(86.6 \%)$ & Significant difference* \\
\hline Exclusively heterosexual & $199(71.3 \%)$ & $84(73.0 \%)$ & $115(70.1 \%)$ & None \\
\hline Race & & & & None \\
\hline White & $98(35.1 \%)$ & $34(29.6 \%)$ & $64(39.0 \%)$ & \\
\hline African American & $33(11.8 \%)$ & $14(12.2 \%)$ & $19(11.6 \%)$ & \\
\hline Asian American & $28(10.0 \%)$ & $10(8.7 \%)$ & $18(11.0 \%)$ & \\
\hline Hispanic & $52(18.6 \%)$ & $27(23.5 \%)$ & $25(15.2 \%)$ & \\
\hline Middle Eastern & $3(1.1 \%)$ & $1(0.9 \%)$ & $2(1.2 \%)$ & \\
\hline Multiracial & $33(11.8 \%)$ & $12(10.4 \%)$ & $21(12.8 \%)$ & \\
\hline Other & $26(9.3 \%)$ & $14(12.2 \%)$ & $12(7.3 \%)$ & \\
\hline Prefer not to answer & $6(2.2 \%)$ & $3(2.6 \%)$ & $3(1.8 \%)$ & \\
\hline \multicolumn{5}{|l|}{ Employed } \\
\hline Unemployed & $76(27.2 \%)$ & $30(26.1 \%)$ & $46(28.0 \%)$ & None \\
\hline 1-39 hours/week & $174(62.4 \%)$ & $73(63.5 \%)$ & $101(61.6 \%)$ & None \\
\hline $40+$ hours/week & $29(10.4 \%)$ & $12(10.4 \%)$ & $17(10.4 \%)$ & None \\
\hline Born in the U.S. & $205(73.5 \%)$ & $86(75.4 \%)$ & $119(72.6 \%)$ & None \\
\hline Mother born in the U.S. & $141(50.5 \%)$ & $53(46.1 \%)$ & $88(53.7 \%)$ & None \\
\hline Father born in the U.S. & $152(54.5 \%)$ & $61(53.0 \%)$ & $91(55.5 \%)$ & None \\
\hline Mother's education ${ }^{\mathrm{b}, \mathrm{c}}$ & 6/6 (1.96) & $6 / 6(2.0)$ & $6 / 6(1.92)$ & None \\
\hline Father's education ${ }^{\mathrm{b}, \mathrm{c}}$ & $6 / 6(1.97)$ & $6 / 6(2.1)$ & $6 / 6(1.91)$ & None \\
\hline
\end{tabular}

Note. Any variable without a superscript includes the number (\%).

${ }^{a}$ mean/median (mode).

${ }^{\mathrm{b}}$ mean/median $(S D)$.

${ }^{c} 1$ = no schooling, $2=1$ st -8 th grade, $3=$ some high school, $4=$ finished high school, $5=$ trade school, $6=$ some college associate degree, $7=4$-year college, $8=$ graduate school.

" There was a significant difference in the gender makeup of students taking PSYC 427 (73.9\% female) relative to those not taking PSYC 427 ( $86.6 \%$ female); $t(204.86)$ $=-2.56, p=0.01$.

We recruited a total of 285 participants at Time 1, and after removing those with incomplete or unreliable data, 278 remained for analysis, 113 of whom took the CESC course. (See Table 1 for a full sample description.) Forty students could not be reached at the end of the semester (Time 2), and eight additional students who responded were removed from the dataset for failing attention checks or exhibiting repeated patterns of extreme or unvarying item response values. Thus, the analysis includes 230 participants at Time 2 . Finally, for the third time point, we were able to reach 193 of our participants, but 16 of the participants were removed due to incomplete data or failed attention checks. Thus, 177 students are included in analysis for Time 3. Students we lost to attrition did not differ significantly from those we retained in terms of demographics or their baseline scores on study variables.

Both the course and control samples were racially and socioeconomically diverse. Reflecting the makeup of the psychology major pool, most participants were female $(79 \%)$, of traditional college age $(M=23.28)$, and 
born in the United States (72\%). The majority of participants reported having a job (72.9\%), with over a third working over 20 hours per week. This level of work is in addition to full-time school for most students: $87.1 \%$ of students reported that they were enrolled full time, and the majority of the sample felt strongly that financial aid or student loans were important to their ability to pay for school tuition. The course and control groups did not differ from each other with the exception of gender: there were significantly more women in the control group than in the course ( $86 \%$ versus $74 \%)$.

\section{Measures}

For reader convenience, Table 2 presents constructs and scales measuring them.

Demographics. For descriptive purposes, participants reported general demographic information, including race, ethnicity, age, and country of birth. For the purposes of study questions, participants also completed measures of social class.

Social class. The measurement of social class is complex, and the literature is clear that strategies must be matched to research questions and population (Diemer et al., 2013). For college students, in prior work we have found that the current level of financial stress, rather than their parents' resources or status or their sense of deprivation while growing up, is the most salient aspect of social class (Cattaneo, Chan, et al., 2019; Rubin et al., 2014).

The College Financial Stress Scale. The College Financial Stress Scale was created by the authors for the purpose of this data collection, and its validation is described in Cattaneo, Chan, et al. (2019). It includes two subscales: the Current Financial Stress subscale includes seven items such as "Currently, considering all of the financial resources I have available, I have more money coming in than I have going out" and "Whatever happens, I am confident I will be financially secure next year” (responses given on a 1-5 Likert scale). The Historical Financial Stress subscale is made up of three items reflecting the level of financial pressure the participant remembers while growing up (e.g., "Growing up, we had to postpone purchasing a needed household item because of its cost”). The reliability of these two scales in the current dataset was .78 (current) and .85 (historical). ${ }^{1}$ We used current financial stress in our analyses.

Attitudes. The civic engagement and service-learning literatures use a wide range of conceptually overlapping measures to assess attitudes; we used four scales that we viewed as relevant to the social justice turn, aiming to include both scales that have been previously validated and those we have adapted or created to cleave more closely to the topics of poverty and social justice.

Civic Attitudes and Skills Questionnaire (CASQ). To measure civic engagement attitudes aligned with social justice, we used the Social Justice Attitudes subscale of the well-validated Civic Attitudes and Skills Questionnaire (Moely, Mercer, et al., 2002). The original CASQ consists of 45 items that are designed to measure students' self-rated outcomes following a service-learning experience. The Social Justice Attitudes (e.g., "We need

1. We report reliability for all measures at baseline but achieved similar results at both follow-up times. 
to institute reforms within the current systems to change our communities”) subscale contains eight items and is answered on a 5-point Likert scale ranging from 1 (strongly disagree) to 5 (strongly agree). Internal consistency was acceptable $(\alpha=.82)$.

Class Privilege Awareness. To evaluate students' awareness of class privilege, we adapted Case's (2007) measure of White privilege. The original seven-item measure has been adapted in the past to assess awareness of gender privilege, and it includes items such as "People living in poverty are disadvantaged in society and people in the middle or upper class are at an advantage" and "People living in poverty and people in the middle or upper class have equal chances at success in this country" (reverse scored). Responses are on a 5-point Likert scale. Because the social justice turn includes not only an awareness of advantage for particular social groups but also an awareness of one's own place in the system that perpetuates that advantage, we added seven items to integrate students' understanding of this aspect of poverty. Items included "Everyone, including me, is part of the system that perpetuates poverty," "There are things that I do that perpetuate poverty," and "People in the middle or upper class earned the advantages they receive" (reverse scored). Reliability was acceptable in this sample $(\alpha=$ .77).

Systems and Individual Responsibility for Poverty (SIRP) Scale. The Systems and Individual Responsibility for Poverty (SIRP) Scale is a 17-item measure developed by a subset of the authors to assess attitudes regarding poverty (Shor et al., 2018). The two subscales, which loaded as two separate factors in prior work, measure attributions of poverty to individual-level causes (e.g., "If you are experiencing poverty in the United States, it is the result of your own skills and abilities") or systemic causes (e.g., "If you are experiencing poverty in the United States, it is the result of problems in our system of education"), respectively. Participants respond on Likert scales ranging from 1 (strongly disagree) to 5 (strongly agree). Scores from the current study demonstrate good internal consistency (SIRP-I $\alpha=.86$; SIRP-S $\alpha=.83$ ).

Implicit Association Test-Classism (IAT-C). The Implicit Association Test (IAT) was initially developed to test for racism (Greenwald et al., 1998, 2009), but it has been adapted to assess implicit bias against many other social identities. We developed a version to assess classism (IAT-C; Shor et al., 2019). Included in over $43 \%$ of implicit social cognition studies, the IAT is the most commonly used measurement tool for implicit processes (Nosek et al., 2011). It is a computer-based sorting task that requires individuals to rapidly match words in target categories (for the IAT-C, people living in poverty and the middle class) with positive and negative attribution labels. Millisecond Software's Inquisit 4 Web calculates effect sizes for participants based on latency response times and errors made during classification. We retained the effect sizes as our measure of implicit classism; negative values indicate stronger negative associations with poverty-related targets, 0 indicates no preference between poverty and middle-class targets, and positive values indicate stronger negative associations toward middle-class targets.

Behavior. Of the many measures available to evaluate civic action, to answer our study questions, we chose four that covered a wide range of behaviors related to addressing social problems.

Civic Engagement Scale-Behavior (CES-B). We used the Civic Engagement Scale's Behavior subscale (Doolittle \& Faul, 2013) to indicate students' general level of participation in community service in the past year. 
It contains six items on a 1 (never) to 7 (always) Likert scale, such as "I help members of my community" and "I stay informed of events in my community.” Internal consistency was good $(\alpha=.84)$.

The Civic Behavior Survey (CBS). We used three subscales from the survey Astin et al. (2006) developed for their longitudinal study of college student service-learning and civic engagement. The Political Expression subscale has seven items, including "Have not bought something or boycotted it because of the social or political values of the company." Participants report the frequency of these behaviors on a 1 (never) to 4 (often) scale. Internal consistency was good $(\alpha=.83)$. The Political Activism scale has five items that are answered yes or no (scored 1 and 0 ), including "participated in protests/demonstrations/rallies" and "expressed your opinion on a community or political issue by contacting or visiting a public official.” Cronbach's alpha was .70.

The third subscale, Working with Communities, measures ways participants might be active in working to address social problems at the community level, both assessing the frequency of participation in particular roles (e.g., "worked on a community project with government agency/program”) and how important a particular goal is to them (e.g., "influencing social values"). The Likert scale for all options was 1 (never or not at all) to 4 (frequently or essential). We adapted the items for relevance to the life stage of our population and time frame of the study. We removed two items referring to participants' "involvement with alma mater" and voting, and we added four items that were relevant to students at the end of their undergraduate career (taking steps toward a career in a helping profession such as gathering information about graduate school or career options, taking a class that

Table 2

Study Constructs, Measures, and Subscale(s) Used

\begin{tabular}{lll}
\hline Construct & Measure & Subscale(s) \\
\hline Social class & College Financial Stress Scale & Current Financial Stress \\
Attitudes & &
\end{tabular}

\begin{tabular}{|c|c|c|}
\hline $\begin{array}{l}\text { Civic engagement attitudes aligned } \\
\text { with social justice }\end{array}$ & $\begin{array}{l}\text { Civic Attitudes and Skills Questionnaire } \\
\text { (CASQ) }\end{array}$ & Social Justice Attitudes \\
\hline $\begin{array}{l}\text { Awareness of privilege related to } \\
\text { social class }\end{array}$ & Class Privilege Awareness & $\mathrm{N} / \mathrm{a}$ \\
\hline Causal attribution for poverty & $\begin{array}{l}\text { Systems and Individual Responsibility } \\
\text { for Poverty Scale (SIRP) }\end{array}$ & $\begin{array}{l}\text { Individual Responsibility (SIRP-I) } \\
\text { Systems Responsibility (SIRP-S) }\end{array}$ \\
\hline Implicit bias related to class & $\begin{array}{l}\text { Implicit Association Test-Classism } \\
\text { (IAT-C) }\end{array}$ & $\mathrm{N} / \mathrm{a}$ \\
\hline \multicolumn{3}{|l|}{ Behavior } \\
\hline $\begin{array}{l}\text { Participation in community service in } \\
\text { past year }\end{array}$ & Civic Engagement Scale & Behavior \\
\hline Political engagement & Civic Behavior Survey & $\begin{array}{l}\text { Political Expression } \\
\text { Political Activism }\end{array}$ \\
\hline $\begin{array}{l}\text { Working to address issues at } \\
\text { community level }\end{array}$ & Civic Behavior Survey & Working With Communities \\
\hline
\end{tabular}

Note. Because the civic engagement literature in general and this study in particular includes many overlapping constructs, we include this table for ease of reference. Further description of scales, sample items, and citations are in the method section. 
involved community service, having a goal of going to graduate school in a helping profession, and having a goal of getting a job in an organization that works to solve social problems). The adapted subscale included 12 items, and reliability was .83 .

\section{Results}

\section{Bivariate Results}

Table 3 presents baseline correlations among all variables. Attitudes are related to one another in the direction one would expect. At baseline, deficit-oriented thinking (blaming individuals for poverty) is related to less systemoriented thinking (blaming systems for poverty; $r=-.30$ ), less awareness of the privilege associated with higher social class status, and lower scores on the attitudes that are supportive of social justice. Similarly, participants with more system-oriented thinking about poverty report stronger social justice attitudes in general.

Table 3

Bivariate Correlations Among Study Variables at Baseline

\begin{tabular}{|c|c|c|c|c|c|c|c|c|}
\hline & 1 & 2 & 3 & 4 & 5 & 6 & 7 & 8 \\
\hline 1. SIRP-I & 1 & & & & & & & \\
\hline 2. SIRP-S & $-.30^{* *}$ & 1 & & & & & & \\
\hline 3. Privilege & $-.51^{* *}$ & $.56^{\prime \prime}$ & 1 & & & & & \\
\hline 4. CASQ-SJ & $-.54^{* *}$ & .50 & $.58^{* *}$ & 1 & & & & \\
\hline 5. IAT & $-.13^{*}$ & .09 & .11 & .03 & 1 & & & \\
\hline 6. Pol Ex & $-.32^{* *}$ & $.23^{\prime \prime}$ & $.33^{* *}$ & $.25^{* *}$ & $.15^{*}$ & 1 & & \\
\hline 7. Pol Act & $-.20^{* \prime}$ & .12 & $.12^{*}$ & $.14^{*}$ & .10 & $.42^{* \prime}$ & 1 & \\
\hline 8. Engage & $-.13^{*}$ & $.13^{\circ}$ & .11 & $.23^{* *}$ & .11 & $.40^{* *}$ & $.32^{* *}$ & 1 \\
\hline 9. Cmmty & $-.16^{\prime \prime}$ & .11 & .04 & $.18^{* \prime}$ & $.12^{*}$ & $.41^{\prime \prime}$ & $.28^{* \prime}$ & $.70^{* *}$ \\
\hline
\end{tabular}

Note. SIRP-I = Systems and Individuals' Responsibilities for Poverty (SIRP) Scale-Individual; SIRP-S = Systems; Privilege = Awareness of Class Privilege; CASQ-SJ = Civic Attitudes and Skills Questionnaire, Social Justice Subscale; IAT = Implicit Association Test-Classism; Pol Ex = Political Expression; Pol Act = Political Action; Engage $=$ Civic Engagement Scale; Cmmty $=$ Working With Communities. $p<0.05$. $" p<0.01$.

\section{Main Analyses Results 1. Changes in Attitudes}

Table 3 presents descriptive statistics for all attitudes and behaviors for each time period. To test whether the differences from time point to time point were significant for the course versus control group, we applied a series of $2 \times 3$ factorial analyses of variance (split-plot ANOVAs) structured for repeated measures. The results are indicated in Table 4 . These analyses test whether there is significant change between time points within the course group as well as whether groups differ from one another at each time point. Assumptions of sphericity were tested, and adjustments were made for one variable (systems responsibility for poverty). Post-hoc $t$-tests were conducted to specify which contrasts were significant. 
Table 4

Mean Scores for Attitudes and Behaviors at Each Time Point

\begin{tabular}{lcccccc}
\hline \multicolumn{7}{c}{ CESC course students } \\
Attitudes & $\mathrm{T} 1$ & $\mathrm{~T} 2$ & $\mathrm{~T} 3$ & $\mathrm{~T} 1$ & $\mathrm{~T} 2$ & $\mathrm{~T} 3$ \\
\hline Implicit & $-.86(.34)$ & $-.75(.39)$ & $-.68(.30)$ & $-.86(.38)$ & $-.79(.40)$ & $-.73(.39)$ \\
Individual blame & $3.05(.74)$ & $2.47(.72)$ & $2.47(.68)$ & $3.12(.71)$ & $3.09(.69)$ & $2.99(.76)$ \\
System blame & $3.54(.60)$ & $4.06(.61)$ & $3.93(.56)$ & $3.41(.65)$ & $3.57(.60)$ & $3.64(.64)$ \\
Privilege & $3.61(.49)$ & $4.01(.45)$ & $3.94(.44)$ & $3.54(.47)$ & $3.58(.50)$ & $3.65(.49)$ \\
Social justice attitudes & $4.08(.55)$ & $4.42(.48)$ & $4.31(.50)$ & $3.99(.55)$ & $4.01(.52)$ & $4.06(.55)$ \\
\hline Behaviors & & & & & & T3 \\
\hline Community work $^{\mathrm{T}}$ & $1.59(.63)$ & & $1.75(.65)$ & $1.63(.63)$ & & $1.64(.70)$ \\
Political action & $0.69(1.29)$ & & $1.60(1.77)$ & $0.81(1.30)$ & & $1.11(1.64)$ \\
Political expression & $2.26(.75)$ & & $2.54(.81)$ & $2.27(.80)$ & & $2.45(.85)$ \\
Civic engagement & $3.84(1.23)$ & & $4.23(1.14)$ & $3.85(1.31)$ & & $3.77(1.39)$ \\
\hline
\end{tabular}

Note. Implicit = IAT Implicit Association Test-Classism; Individual blame = Systems and Individuals' Responsibilities for Poverty (SIRP) Scale-Individual; System blame = SIRP Scale-Systems; Privilege $=$ Awareness of Class Privilege; Social justice attitudes $=$ Civic Attitudes and Skills Questionnaire, Social Justice Subscale; Community work = Working With Communities.

${ }^{a}$ Time 2, just after the end of the semester, is not included for behaviors because it includes activities that were required by the course.

The repeated-measures ANOVAs revealed significant group by time point interactions, indicating that course students changed significantly during the semester for all attitudes except implicit bias. Specifically, with respect to poverty, course students reported blaming individuals less and systems more. They also reported increased awareness of privilege, and they endorsed greater social justice attitudes after taking the course. The course and control groups' scores were statistically identical on all variables at baseline, but at the end of the semester, the control group had changed on just one variable. At the end of the semester, the control group had increased their blame of systems for poverty, though course students increased significantly more (mean difference of .13 versus $.51)$.

As a post-hoc exploration, we evaluated correlations among the change scores for each attitude variable, investigating how attitude changes were interrelated. We found that both change in system and individual attributions were related to change in awareness of privilege and social justice attitudes and that change in privilege awareness and social justice attitudes were related to each other ( $r$ range from .19 to .40, $p<.01$ ). However, we found no correlation between the change in systemic attributions and the change in individual attributions for poverty.

The same repeated-measures ANOVAs supported the hypothesis that post-course changes would be sustained one year later. Though three of four changed attitudes regressed to a statistically significant degree (systems responsibility for poverty, social justice attitudes, and awareness of privilege), the course group remained significantly higher than the control group on these variables one year post-course. In sum, while there was attenuation, the course had a significant impact on four of five attitudes just after the course and a year after the class concluded. 


\section{Main Analyses Results 2. Differences in Behavior at One Year Post-Course}

A two-way repeated measures ANOVA compared the control and course groups' behavior from pre-semester to one year post-semester. Two types of behavior changed for the course group, as indicated by a significant time by group interaction, and two did not; the control group showed no significant behavior change in any of the four variables. The course group increased their general civic engagement $(F(1,173)=4.35, p<.05, \eta 2=.032$; see Table 4 for means and Figure 1a for the comparison between groups at pre-semester and one year post-semester) and their political activism $(F(1,173)=8.43, p<.01, \eta 2=.046$; see Table 4 for means and Figure $1 \mathrm{~b}$ for a graphic representation of the interaction). The course showed no significant impact on measures of political expression or working with communities.

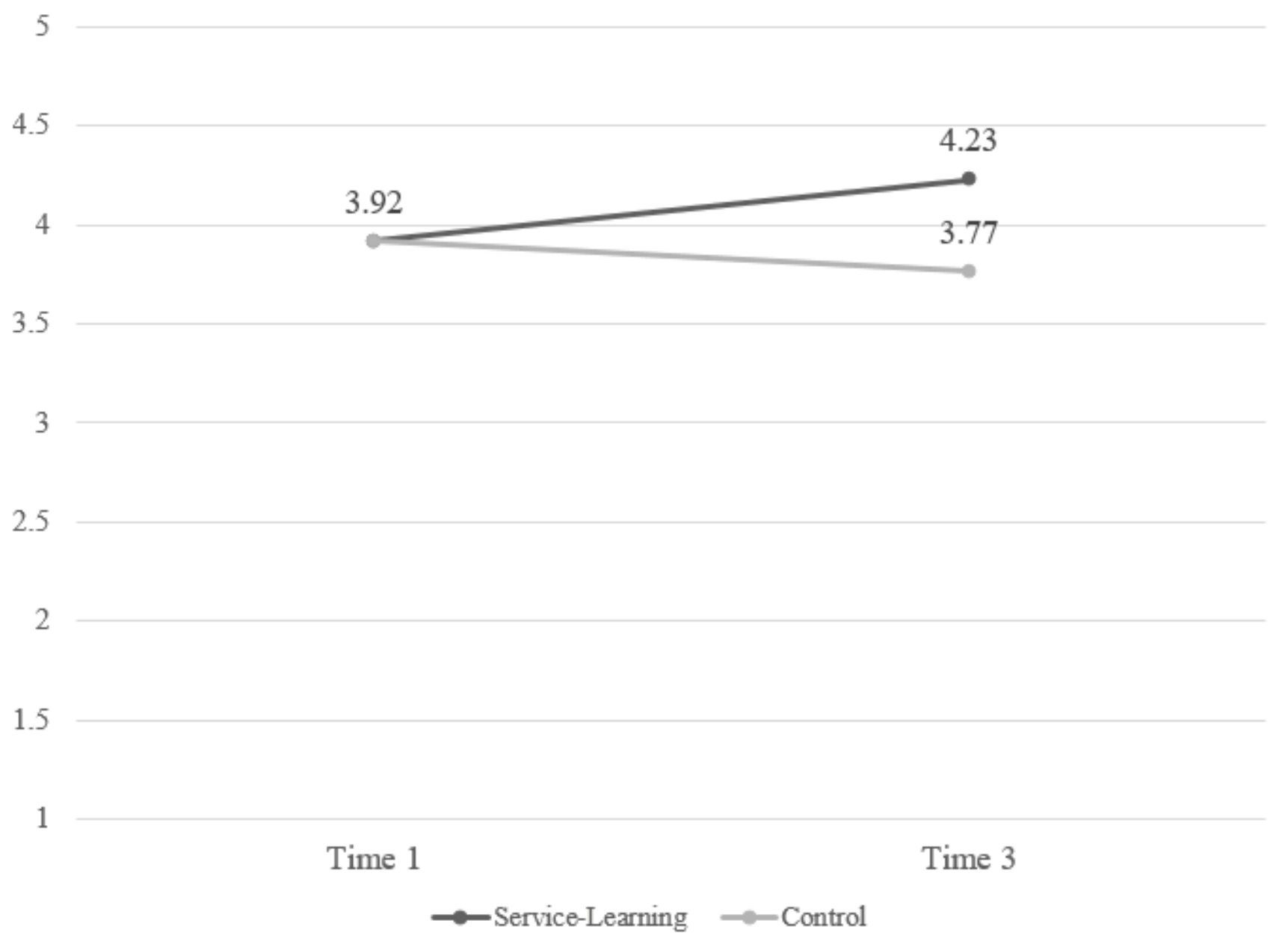

Figure 1a. Comparison of Means for General Civic Engagement at Time 1 (pre-semester) and Time 3 (one year post-semester), Service-Learning vs. Control Group Students 
Table 5

Results of Repeated Measures Analyses of Variance (ANOVAs) for Attitude Change From Pre-to Post-Semester and One Year Later, Comparing Service-Learning and Control Students (“Groups")

Predictor

Sources of variance

Sum of squares

$d f \quad$ Mean square

F

$p$

Partial $\eta^{2}$

Awareness of privilege

Between subjects

Groups

Error

Within subjects
Time

Group $\times$ time

Error (time)

$9.99 \quad 1$

87.93

162

\subsection{3}

3.26

21.98

2
2
324

324

18.41

.000

.102

.54

1.67

1.63

24.56

.000

132

24.01

.000

.129

.07

Social justice attitudes

Between subjects

Groups

Error

Within subjects

7.92
99.45

99.45

1

160
7.92

.62

Time

$\begin{array}{rr}2.02 & 2 \\ 2.42 & 2 \\ 28.43 & 320\end{array}$

Error (time)

28.43

1.01
1.21
.09

11.36

13.63

.000

.000

.000

.070

12.75

(1)

Implicit associations

Between subjects

$$
\begin{aligned}
& \text { Groups } \\
& \text { Error }
\end{aligned}
$$

.18

19.35

58

1.18

.33

.53

.468

.009

Within subjects

Time
Group $\times$ time
Error (time)
responsibility for poverty

Individual responsibility for poverty

Between subjects

Groups
Error

\section{.123}

.014

9.61

2
2
116

2

116

.06

.01

.08

33

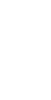

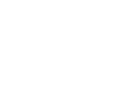

$9.61 \quad 116$

\begin{tabular}{llll}
.06 & .74 & .48 & .013 \\
.01 & .08 & .92 & .001 \\
.08 & & & \\
\hline
\end{tabular}




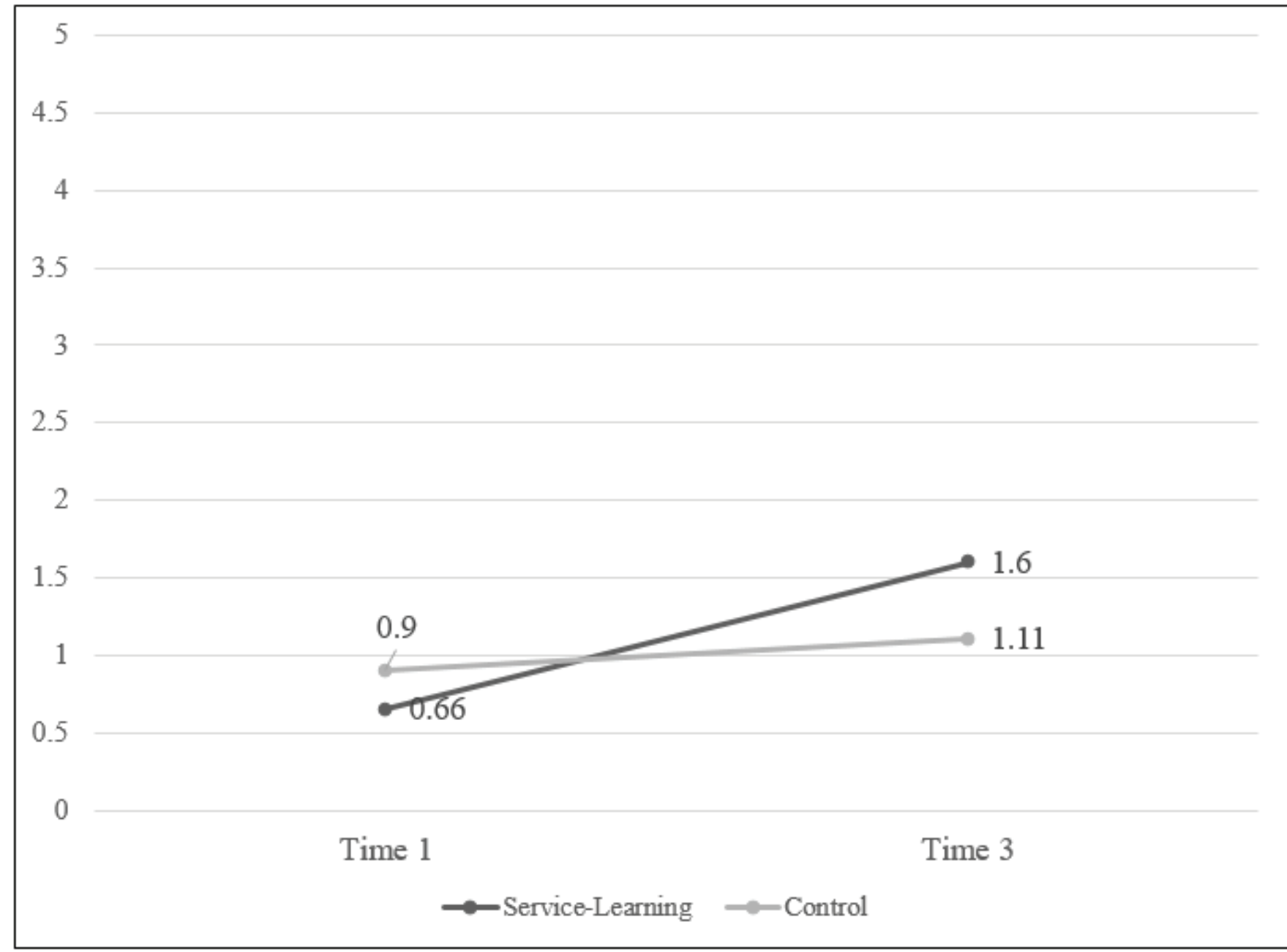

Figure 1b. Comparison of Means for Political Activism at Time 1 (pre-semester) and Time 3 (one year post-semester), Service-Learning vs. Control Group Students

Table 6 Regression of Attitudes on Behaviors That Changed Over the Course of the Semester

\begin{tabular}{lcccccc}
\hline & \multicolumn{3}{c}{ Political action } & \multicolumn{3}{c}{ General civic engagement } \\
\cline { 2 - 7 } Variable & $B$ & $S E B$ & $\beta$ & $B$ & $S E B$ & $\beta$ \\
\hline Course student & -.05 & .31 & -.01 & .20 & .24 & .07 \\
SIRP-I & -.52 & .24 & $-.22^{*}$ & .19 & .19 & .11 \\
SIRP-S & .29 & .30 & .11 & -.21 & .23 & -.10 \\
Privilege & .22 & .42 & .07 & .39 & .32 & .15 \\
CASQ-SJ & -.23 & .38 & -.07 & .62 & .30 & $.25^{*}$ \\
$R 2$ & & .08 & & & .08 & $2.91^{*}$ \\
$F(5,162)$ & & $2.74^{*}$ & & & & \\
\hline
\end{tabular}

Note. Course student $=$ the student enrolled in the service-learning course, $0=$ no, $1=$ yes; SIRP-I $=$ Systems and Individuals' Responsibilities for Poverty (SIRP) Scale-Individual; SIRP-S = Systems; Privilege = Awareness of Class Privilege; CASQ-SJ = Civic Attitudes and Skills Questionnaire, Social Justice Subscale. " $p<.05$. 


\section{Main Analyses Results 3. Cognitive Mechanisms for Behavioral Course Effects}

Our third hypothesis posited the attitudes that changed during the semester would predict behavior changes one year later. To test that hypothesis, we conducted multiple regressions to predict the two types of civic behavior that changed-civic engagement and political activism. As predictors, we entered all attitude variables as measured at the end of the semester (Time 2), along with a dummy-coded variable indicating course versus control group. Both regression models explained a greater percentage of the variance than would be achieved by chance, and both included one significant predictor above and beyond the other attitudes. Individual attributions for poverty was the significant predictor of political action, and general social justice attitudes predicted general civic engagement (see Table 6).

\section{Main Analyses Results 4. Social Class Moderation}

Finally, in order to explore whether students' own social class influenced their attitude shifts in the course, we used hierarchical regression models. In the first block, we entered the baseline attitude and financial stress; in the second block, we entered the interaction between the two. The dependent variables were each of the four attitude variables as measured at the end of the semester. We found that current financial stress was significantly related to the change in systems responsibility for poverty, in that both the interaction term and overall model was statistically significant $(F(1,95)=3.93, p=.05, \Delta R 2=.028)$. The same was true for the model predicting individual blame for poverty $(F(1,95)=4.26, p=.04, \Delta R 2=.024)$. We probed these interactions by testing the conditional change in attributions at high, medium, and low levels of financial stress. For individual blame for poverty, all students decreased significantly, but students experiencing low financial stress decreased the least, and students experiencing high financial stress decreased the most. Conversely, for systemic blame for poverty, all three groups increased, but students experiencing low financial stress increased the most, and those experiencing high financial stress increased the least (see Figures $2 \mathrm{a}$ and $2 \mathrm{~b}$ ).

\section{Discussion}

\section{Results of Hypothesis Tests Add Nuance to Previous Work}

In a course that focuses explicitly on teaching students to see the social causes of social problems, we found that students' deficit-oriented thinking (blaming individuals for social problems) decreased, and system-level thinking increased. This change was present in the three scales specific to the primary focus of the course (poverty) as well as in the measure that assesses broader social justice attitudes. This finding is consistent with prior work showing significant attitude change resulting from service-learning courses (Conway et al., 2009), underscoring its relevance to a course in which social justice-oriented content is centered. Furthermore, the changes in our 


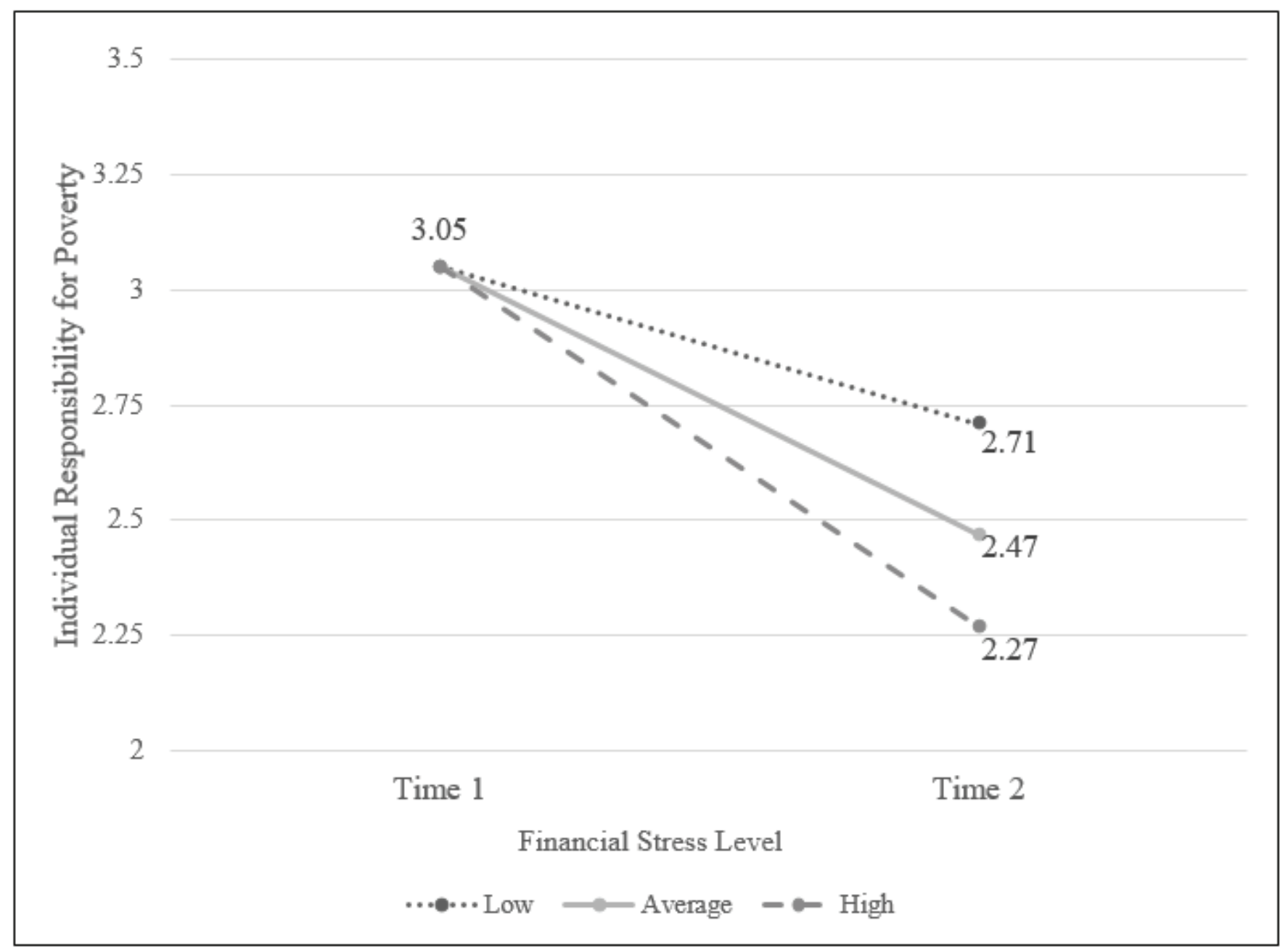

Figure 2a. Financial Stress as a Moderator of Change in Service-Learning Course Students' Attitudes About Individual Responsibility for Poverty

course were still present a year after it ended, though they did attenuate slightly. These findings are again consistent with the impact of service-learning over time (Astin et al., 2006) and provide evidence supporting the power and potential of this pedagogy.

In addition to directly supporting the effectiveness of this example of a social justice turn, our findings add important nuance to the literature on attitude change in two ways. The first key contribution is the finding that deficit-oriented and system-oriented thinking do not move in tandem. While we had reported this finding crosssectionally (Cattaneo, Shor, et al., 2019), here we discovered that in addition to a weak correlation at baseline (.3), the change in the two scales is not correlated and that these constructs are related to different types of action a year after the course. This finding has pedagogical implications. It suggests that simply introducing information about systemic causes of problems is not enough to reduce the degree to which students blame individuals for the same problems, nor is course material targeting deficit-oriented thinking sufficient to raise students' awareness of the systemic underpinnings of social issues. These attitudes, and the techniques that change them, need to be considered separately. 


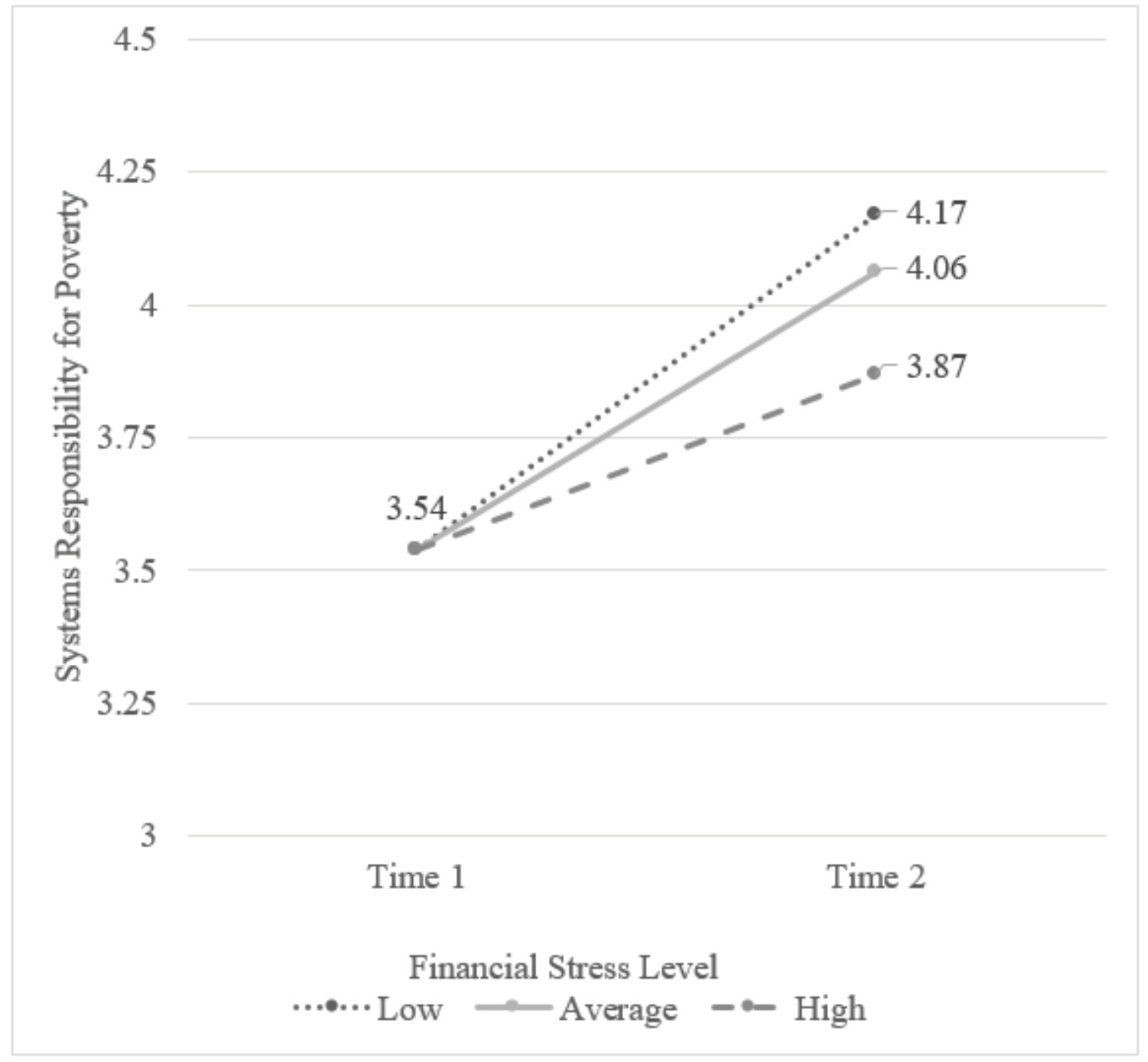

Figure 2b. Financial Stress as a Moderator of Change in Service-Learning Course Students' Attitudes About Systems Responsibility for Poverty

Second, in a growing and controversial area of scholarship, it has become evident that implicit bias can influence behavior (Banaji \& Greenwald, 2013), and we found that our course did not change implicit bias against people in poverty. It may be that a class like ours does not expose students to the information they would need in order to change implicit bias. Implicit associations link together stimulus and response; in our class, students are exposed to the difficulty, injustice, and pain associated with poverty. Shifting implicit bias may require a more intentional exposure to people in poverty doing things that are counter-stereotypical. In the two studies cited earlier (Barney et al., 2017; Kogan \& Schoenfeld-Tacher, 2018), in which service-learning was linked with implicit bias change, the service experiences were not of the helper-help recipient variety and therefore may have been more effective at changing the associations between the stigmatized groups and negative descriptors. In general, these kinds of exposures have been shown to at least temporarily decrease implicit bias (Banaji \& Greenwald, 2013), though long-term change remains elusive. Neither of the service-learning implicit bias studies had follow-up periods that went beyond the end of the course. 
With respect to behavior, we again found general support for the idea that service-learning changes behavior, adding to the body of longitudinal work that shows that the change lasts beyond the end of the semester. Here again, we found nuance in that not all types of civic action changed. We found that overall civic engagement increased, whereas the scale specific to working with communities did not. The overall civic engagement scale is broad enough to capture the full range of ways students might engage; it also includes a question that captures what we know happens regularly in the course-students continue volunteering at their placements. It may be that students who continue volunteering in this way make up the bulk of the difference in aggregate scores. This finding is not trivial: continuing to volunteer past the end of the course likely builds efficacy and opens up the possibility that other opportunities will arise that will allow the student to expand their engagement. However, it may suggest that action builds very specifically on the experiences offered in class.

We also found that political behavior changed in one way (activism) but not another (expression). In an earlier study, Harker (2016) reported that a service-learning course increased political consciousness but not political action. These differences require more rigorous exploration; it may be that students need scaffolding around how to translate their changed attitudes into behavior. Adding evidence to this possibility, the item on the political action scale that showed the biggest difference between course and control students at Time 3 was participating in "community service or volunteering at a political organization." In responding to this possibility, it is possible that students were referring to behavior that occurred at their placement organizations, which are not primarily focused on political action but may offer students some opportunities along these lines. The attitudes most predictive of these behaviors also varied: a decrease in deficit-oriented thinking was the most powerful predictor of political activism, and general social justice attitudes most strongly predicted general engagement. Again, these results suggest specificity in the links between attitude and behavior - a theme with pedagogical implications.

Finally, the results of this study confirm that the ways in which students struggle with social problems themselves is likely to have an influence in their experience of the course. Importantly, we found that on average, students at all levels of financial stress changed significantly on the variables of interest-they decrease their blame of individuals and increase their system attribution for poverty. However, the degree of change on the variables most central to our course varied by the level of financial stress they reported. More personal financial stress was associated with a bigger decrease in blaming individuals for poverty and a smaller increase in blaming systems for poverty. Conversely, those reporting the least personal financial stress changed the least in their blame of individuals and increased their blame of systems the most. The fact that different groups experienced the most change on these two variables underscores the idea that one can hold both of these ideas at once-people under financial stress who change how much they blame individuals may not begin to blame systems a great deal more. In fact, as we have noted, change in individual and system attributions is uncorrelated. For those under financial stress, it may be that the nature of struggling with economic hardship is normalized or humanized, leading them to blame individuals (including themselves, perhaps) less. However, blaming systems instead may reduce their sense of control. System justification theory, in which people are motivated to believe that the status quo is fair, even when faced with evidence to the contrary, is relevant here (Jost et al., 2004). It may be that talking directly about what it would mean to believe systems are at fault could help students note and contend with this dissonance.

With regard to system attribution, it may be that those who experience the least financial stress are least affected 
by seeing the unfairness in systems and so have an easier time with increasing those attributions. For example, if I come to believe that the education system is arranged to favor those who have wealth, I may not like that realization, but if it does not affect me or people like me, I may have an easier time accepting it. However, decreasing deficit thinking may stir up guilt for those who are not struggling and may lead them to question the idea that they deserve the advantages they enjoy. Again, focusing on this dissonance might produce rich conversation and different levels of change. We did not measure the experiences of uncomfortable emotion that may have played a role in these findings, and future research might delve more deeply into that area.

\section{Limitations}

The implications of our findings are framed by a number of limitations. First, the generalizability of the findings is limited by the fact that we explored only one course, at one university, in one region of the country. We specify the aspects of the course that we believe generalize to the pedagogy in general, but further work is required to test that generalizability. Second, several of our key measures are relatively new and were developed using the same population in which this study was conducted. While the consistency of results across more established measures such as the CASQ add to our confidence in the findings, the measures require more testing to build evidence for their validity. Additionally, in exploring the role of social identity in student experience of the course, we evaluated only social class. Social class intersects with other identities (e.g., race, gender) to produce experience in college as elsewhere (Cattaneo, Chan, et al., 2019; Langhout et al., 2009), and the full richness of that picture was not included in this study. We also did not track several aspects of student experience that might have added to our understanding of findings and would be worth adding in future work. For example, we did not have access to any objective measures of social class, such as eligibility for financial aid; we did not track how close students were to graduation or whether they had graduated at the time of follow-up; and we did not collect information about which students had which placements. Finally, sample attrition over three time points was significant, leaving a smaller sample than we would have liked at the final follow-up. Here again, the consistency of findings adds credence to results, but replication is certainly warranted.

\section{Implications for Pedagogy and Research}

The results of this study provide a concrete example of coursework with an intentional focus on social justice and provide evidence that this approach shifts the attitudes that are central to that perspective. Several findings stand out in terms of implications for pedagogy and future research. First, the distinction between individual and system attributions has important implications for pedagogy. Awakening students to systemic oppression does not ensure that they will blame the individuals who suffer from that oppression less, and vice versa. It is necessary to target both attitudes.

Similarly, shifting explicit attitudes does not naturally shift implicit bias, and strategies for doing so must be considered separately. Scholarship on implicit bias provides some clues about approaches that might be effective, 
beyond ensuring that students have direct contact with stigmatized groups. In recent years (post-data collection), consistent with the social justice turn, we have included more sources from people who have experienced poverty themselves and are doing things such as attending graduate school and starting businesses, and we have included cooperative models that build capacity within communities. We have increased the variety of sources, such as speakers, blog posts, and other media, in order to amplify these voices and ideas. Exposure to this kind of information may influence implicit bias, but these techniques deserve further exploration.

Additionally, research suggests that reflecting on implicit bias in class may be its own educational technique (Sukhera et al., 2019). Indeed, if as we found in this course, implicit bias does not shift with respect to poverty with this type of experience, the next important step may be to educate students about that disparity. Students may need to understand that their gut reactions will not change along with their explicit opinions and that their choices need to be informed by that understanding.

Our findings with respect to social class suggest first that it is critical to consider how students' identities and life experiences affect the way they think about and emotionally respond to the material they are learning. These findings are important to consider for students across the social class continuum. As with implicit bias, sharing information about how we learn and what leads us to cling more tightly to previously established beliefs might help students be more intentional and self-aware in this process.

The findings related to behavior highlight the fact that our service opportunities do not reach the ideal of critical service. Students' actions do not change in terms of political expression and working with communities, and their increase in political action may be largely driven by continuing to volunteer for their placements. It may well be that students do not know how to translate their changed attitudes into more system-oriented action. We pay significant attention to the disparity between our system focus in class and the individual focus in placements, both in our reflections and class discussions, which does match the critical service spirit and likely strengthens attitude change. However, in order to engage in effort geared explicitly toward social change, courses may need to include this kind of action in their service requirements; these experiences show students through experience that they are capable of enacting their changing values in these specific ways (Stanlick, 2015).

\section{First Author's Reflection}

One of my greatest struggles as an instructor of this course is the knowledge that critical consciousness can crush hope-and that this is more deeply true for some students than others. Put simply, it is profoundly depressing to understand the embeddedness of structural oppression and to witness its impact on individual human beings. I have heard students struggling with the impact of their increase in consciousness-sometimes openly in class, sometimes in their reflections, and in a few cases after the end of the course. As a White, cis-gender woman whose visible identities indicate privilege, I know that many of my students are more personally affected by the topics we discuss than I am, and I know that they may assume that too. As the results of this study show, and as my anecdotal experiences have repeatedly suggested to me, this personal resonance absolutely affects their experience in the class. In fact, experiential learning demands of students that they open themselves up to this personal resonance; to encounter a "disorienting dilemma" and truly engage with it requires openness to whatever it triggers. 
Whether or not reflections ask students to reflect on personal feelings and experiences, they are likely to surface in the process of what we are asking students to do.

Over time I have developed strategies to manage these tensions. As noted earlier, I bring in examples of social change, particularly change that is initiated from within communities, and I name and discuss the discomfort students are likely to feel over the semester. I have also learned to seek out my own experiential learning and to bring my authentic self to the classroom, joining with the students in their struggle. There is no formula (at least that I have found) for "joining with" the students—doing it productively requires ongoing calculation that reminds me of decisions around disclosure in clinical practice. When tempted to bring oneself into the conversation, the first step is to explore that temptation: Am I sharing for my own comfort? To model? To explain? The decision of what to share requires some of what we ask of the students - to sit with discomfort and act with clear intention.

I seek out my own experiential learning to bring into this process in two primary ways. Perhaps most straightforward, after a couple of years teaching this course, I assigned myself a placement similar to my students. I sought out an organization that focused on homelessness in my neighborhood and offered myself as a long-term volunteer. I did this out of a personal desire to "walk the talk," but it has had the added benefit of guiding me to think more deeply about how students' service experiences might stir up different kinds of reactions, and it allows me to talk to them about that knowledgeably.

I also intentionally engage in a process of understanding my own positionality and how it shapes my views and interactions. This engagement involves scholarly exploration, including reading, but much more powerfully, it involves relationships. I work to build a varied personal and professional network, including a diverse set of graduate and undergraduate students collaborating with me. In my research lab, we talk a great deal about our identities and their impact on our experiences. Including students who also teach this class, or who took this class, in the lab has allowed us to have those discussions related to the material and to broaden our understanding of what students were experiencing as a result. Carrying out research and writing publications related to the class with students who have taught or taken it has facilitated and deepened these conversations.

As a result of these experiences, I have become more acutely aware of the perils and possibilities associated with my social identities in the classroom. I am aware of a power differential between my students and me both in terms of social privilege outside the classroom, in many cases, and in terms of my privilege within the classroom, in all cases. As instructor, if I choose, I can avoid the vulnerability we ask of students. I set the intention to move toward that vulnerability personally and to share it in the classroom to model and teach. By making use of my own journey with critical consciousness, I attempt to guide students' productive navigation of the natural tension between that consciousness and hope for positive change.

\section{References}

Astin, A. W., Vogelgesang, L. J., Misa, K., Anderson, J., Denson, N., Jayakumar, U., Saenz, V., \& Yamamura, E. (2006). Understanding the effects of service-learning: A study of students and faculty. Higher Education Research Institute, University of California, Los Angeles. 
Banaji, M. R., \& Greenwald, A. G. (2013). Blind spot: Hidden biases of good people. Random House.

Barney, S. T., Corser, G. C., Strosser, G. L., Hatch, D. L., \& LaFrance, K. (2017). Service-learning in abnormal psychology: Softening the implicit stigma against the mentally ill. Scholarship of Teaching and Learning in Psychology, 3(2), 151-162. https://doi.org/10.1037/st10000083.

Bronfenbrenner, U., \& Ceci, S. J. (1994). Nature-nurture reconceptualized in developmental perspective: A bioecological model. Psychological Review, 101(4), 568-586.

Case, K. A. (2007). Raising male privilege awareness and reducing sexism: An evaluation of diversity courses. Psychology of Women Quarterly, 31(4), 426-435. https://doi.org/10.1111/j.1471-6402.2007.00391.x.

Cattaneo, L. B., Chan, W. Y., Shor, R., Gebhard, K. T., \& Elshabassi, N. H. (2019). Elaborating the connection between social class and classism in college. American Journal of Community Psychology, 63(3-4), 476-486. https://doi.org/10.1002/ajcp.12322.

Cattaneo, L. B., Shor, R., Calton, J. M., Gebhard, K. T., Buchwach, S. Y., Elshabassi, N., \& Hargrove, S. (2019). Social problems are social: Empirical evidence and reflections on integrating community psychology into traditional curriculum. Global Journal of Community Psychology Practice, 10(1), 1-29. http://www.gjcpp.org.

Celio, C. I., Durlak, J., \& Dymnicki, A. (2011). A meta-analysis of the impact of service-learning on students. Journal of Experiential Education, 34(2), 164-181. https://doi.org/10.1177/105382591103400205.

Conley, P. A., \& Hamlin, M. L. (2009). Justice-learning: Exploring the efficacy with low-income, first-generation college students. Michigan Journal of Community Service Learning, 16(1), 47-58.

Conner, J., \& Erickson, J. (2017). When does service-learning work? Contact theory and service-learning courses in higher education. Michigan Journal of Community Service Learning, 23(2), 53-65.

Conway, J. M., Amel, E. L., \& Gerwien, D. P. (2009). Teaching and learning in the social context: A metaanalysis of service learning's effects on academic, personal, social, and citizenship outcomes. Teaching of Psychology, 36(4), 233-245. https://doi.org/10.1080/00986280903172969.

Diemer, M. A., Mistry, R. S., Wadsworth, M. E., López, I., \& Reimers, F. (2013). Best practices in conceptualizing and measuring social class in psychological research. Analyses of Social Issues and Public Policy, 13(1), 77-113. https://doi.org/10.1111/asap.12001.

Doolittle, A. \& Faul, A. (2013). Civic Engagement Scale: A validation study. Sage Open, 3(3), 1-7. https://doi. org/10.1177\%2F2158244013495542.

Eyler, J., \& Giles, D. E., Jr. (1999). Where's the learning in service-learning? Jossey-Bass.

Grain, K. M., \& Lund, D. E. (2016). The social justice turn: Cultivating "critical hope" in an age of despair. Michigan Journal of Community Service Learning, 23(1), 45-59.

Greenwald, A.G., McGhee, D.E., \& Schwartz, J.L.K. (1998). Measuring individual differences in implicit cognition: The Implicit Association Test. Journal of Personality and Social Psychology, 74, 1464-1480.

Greenwald, A. G., Poehlman, T. A., Uhlmann, E. L., \& Banaji, M. R. (2009). Understanding and using the Implicit Association Test: III. Meta-analysis of predictive validity. Journal of Personality and Social Psychology, 97(1), 17-41. https://doi.org/10.1037/a0015575.

Harker, D. (2016). Political consciousness but not political engagement: Results from a service-learning study. Michigan Journal of Community Service Learning, 22(2), 31-47. 
Henry, S. E. (2005). "I can never turn my back on that": Liminality and the impact of class on service-learning experience. In D. W. Butin (Ed.), Service-learning in higher education: Critical issues and directions (pp. 4566). Palgrave Macmillan.

Hofmann, W., Gawronski, B., Gschwendner, T., Le, H., \& Schmitt, M. (2005). A meta-analysis on the correlation between the Implicit Association Test and explicit self-report measures. Personality and Social Psychology Bulletin, 31(10), 1369-1385. https://doi.org/10.1177/0146167205275613.

Holsapple, M. A. (2012). Service-learning and student diversity outcomes: Existing evidence and directions for future research. Michigan Journal of Community Service Learning, 18(2), 5-18.

Jost, J. T., Banaji, M. R., \& Nosek, B. A. (2004). A decade of system justification theory: Accumulated evidence of conscious and unconscious bolstering of the status quo. Political Psychology, 25(6), 881-919. https://doi. org/10.1111/j.1467-9221.2004.00402.x.

King, M. L., Jr. (1968). The role of the behavioral scientist in the civil rights movement. Journal of Social Issues, 24(1), 1-12. https://doi.org/https://doi.org/10.1111/j.1540-4560.1968.tb01465.x.

Kogan, L. R., \& Schoenfeld-Tacher, R. M. (2018). Participation in an intergenerational service learning course and implicit biases. Educational Gerontology, 44(2-3), 90-98. https://doi.org/10.1080/03601277.2017.141 3784.

Langhout, R. D., Drake, P., \& Rosselli, F. (2009). Classism in the university setting: Examining student antecedents and outcomes. Journal of Diversity in Higher Education, 2(3), 166-181. https://doi.org/10.1037/ a0016209.

Lee, J. J. (2005). Home away from home or foreign territory? How social class mediates service-learning experiences. NASPA Journal, 42(3), 310-325. https://doi.org/10.2202/1949-6605.1510.

Marullo, S., \& Edwards, B. (2000). From charity to justice: The potential of university-community collaboration for social change. American Behavioral Scientist, 43(5), 895-912.

Mezirow, J. (2000). Learning as transformation: Critical perspectives on a theory in progress. Jossey-Bass.

Mitchell, T. D. (2008). Traditional vs. critical service-learning: Engaging the literature to differentiate two models. Michigan Journal of Community Service Learning, 14(2), 50-65.

Mitchell, T. D. (2013). How service-learning enacts social justice sensemaking. Journal of Critical Thought and Praxis, 2(2), 6. https://doi.org/https://doi.org/10.31274/jctp-180810-22.

Mitchell, T. D., Donahue, D. M., \& Young-Law, C. (2012). Service learning as a pedagogy of whiteness. Equity and Excellence in Education, 45(4), 612-629. https://doi.org/10.1080/10665684.2012.715534.

Moely, B. E., McFarland, M., Miron, D., Mercer, S., \& Ilustre, V. (2002). Changes in college students' attitudes and intentions for civic involvement as a function of service-learning experiences. Michigan Journal of Community Service Learning, 9(1), 18-26.

Moely, B. E., Mercer, S. H., Ilustre, V., Miron, D., \& McFarland, M. (2002). Psychometric properties and correlates of the Civic Attitudes and Skills Questionnaire (CASQ): A measure of students' attitudes related to service-learning. Michigan Journal of Community Service Learning, 8, 15-26.

Nosek, B. A., Hawkins, C. B., \& Frazier, R. S. (2011). Implicit social cognition: From measures to mechanisms. Trends in Cognitive Sciences, 15(4), 152-159. https://doi.org/10.1016/j.tics.2011.01.005. 
Novak, J. M., Markey, V., \& Allen, M. (2007). Evaluating cognitive outcomes of service learning in higher education: A meta-analysis. Communication Research Reports, 24(2), 149-157. https://doi. org/10.1080/08824090701304881.

Oswald, F. L., Mitchell, G., Blanton, H., Jaccard, J., \& Tetlock, P. E. (2013). Predicting ethnic and racial discrimination: A meta-analysis of IAT criterion studies. Journal of Personality and Social Psychology, 105(2), 171-192. https://doi.org/10.1037/a0032734.

Rubin, M., Denson, N., Kilpatrick, S., Matthews, K. E., Stehlik, T., \& Zyngier, D. (2014). “I am working-class”: Subjective self-definition as a missing measure of social class and socioeconomic status in higher education research. Educational Researcher, 43(4), 196-200. https://doi.org/10.3102/0013189X14528373.

Rubin, M., \& Wright, C. L. (2017). Time and money explain social class differences in students' social integration at university. Studies in Higher Education, 42(2), 315-330. https://doi.org/10.1080/03075079.2015.10 45481.

Ryan, W. (1971). Blaming the victim. Pantheon Books.

Shor, R., Calton, J. M., \& Cattaneo, L. B. (2018). The development of the Systems and Individual Responsibility for Poverty (SIRP) Scale. Journal of Community Psychology, 46(8), 1010-1025. https://doi.org/https:// doi.org/10.1002/jcop.22088.

Shor, R., Cattaneo, L. B., \& Alexander, L. (2019). Assessing implicit and explicit attitudes about classism. Journal of Poverty, 23(6), 487-504. https://doi.org/10.1080/10875549.2019.1616035.

Stanlick, S. (2015). Getting “real” about transformation: The role of brave spaces in creating disorientation and transformation. Michigan Journal of Community Service Learning, 22(1), 117-121.

Sukhera, J., Wodzinski, M., Rehman, M., \& Gonzalez, C. M. (2019). The Implicit Association Test in health professions education: A meta-narrative review. Perspectives on Medical Education, 8(5), 267-275. https:// doi.org/10.1007/s40037-019-00533-8.

Tinto, V. (2006). Research and practice of student retention: What next? Journal of College Student Retention: Research, Theory and Practice, 8(1), 1-19. https://doi.org/10.2190/4YNU-4TMB-22DJ-AN4W.

Warren, J. L. (2012). Does service-learning increase student learning? A meta-analysis. Michigan Journal of Community Service Learning, 18(2), 56-61.

Whitley, C. T., \& Yoder, S. D. (2015). Developing social responsibility and political engagement: Assessing the aggregate impacts of university civic engagement on associated attitudes and behaviors. Education, Citizenship and Social Justice, 10(3), 217-233. https://doi.org/10.1177/1746197915583941.

Yeh, T. L. (2010). Service-learning and persistence of low-income, first-generation college students: An exploratory study. Michigan Journal of Community Service Learning, 16(2), 50-65.

Zembylas, M., \& McGlynn, C. (2012). Discomforting pedagogies: Emotional tensions, ethical dilemmas and transformative possibilities. British Educational Research Journal, 38(1), 41-59. https://doi.org/10.1080/01 411926.2010 .523779 . 


\section{Author Note}

Lauren B. Cattaneo, Department of Psychology, George Mason University; Jenna M. Calton, Department of Psychology, George Mason University; Rachel Shor, Department of Psychology, George Mason University; Syeda I. Younus, Department of Psychology, George Mason University; Kris T. Gebhard, Department of Psychology, George Mason University; Stephanie Hargrove, Department of Psychology, George Mason University; Nour Elshabassi, Department of Psychology, George Mason University; Batool Al-Shaar, Department of Psychology, George Mason University.

Jenna M. Calton is now at Maven Psychology Group in Bethesda, MD; Kris T. Gebhard is now at Center Focused Therapy in Chicago, IL. This research was supported with a grant from the Spencer Foundation. Correspondence concerning this article should be addressed to Lauren B. Cattaneo, Department of Psychology, George Mason University, 4400 University Drive, MSN 3F5, Fairfax, VA, 22030. E-mail: LCattane@gmu.edu. 